\title{
Práticas de atividades turísticas em Unidades de Conservação: o contexto dos parques urbanos em Manaus - AM
}

\author{
Tourism activities in Conservation Units: the context of urban parks in Manaus - AM \\ Prácticas de actividades turísticas en Unidades de Conservación: el contexto de los parques urbanos en Manaus \\ - AM
}

Ítalo Thiago Loiola Soares Lima

Universidade do Estado do Amazonas (UEA), Brasil

DOI: https://doi.org/10.18472/cvt.19n1.2019.1449

loiola.italo@gmail.com

Redalyc: http://www.redalyc.org/articulo.oa?

$\mathrm{id}=115459473015$

\author{
Márcia Raquel Cavalcante Guimarães \\ Universidade do Estado do Amazonas (UEA), Brasil \\ mguimaraes@uea.edu.br
}

Recepção: 18 Junho 2017

Aprovação: 22 Novembro 2018

\section{Resumo:}

O desenvolvimento da atividade turística em ambiente de Unidades de Conservação se dá na necessidade da conexão entre homem e o meio natural e, por meio dessa ligação, pode contribuir de forma qualitativa na preservação, propagação e uso sustentável dos espaços verdes. E, para que essa atividade possa ser desenvolvida de forma positiva e não predatória, é necessário que seja planejada e tenha um sentido totalmente sustentável. A grande procura por essas áreas naturais, em sua maioria por Unidades de Conservação, implica em fatores positivos na relação do homem com a natureza, na educação e consciência ambiental, práticas sustentáveis e a proteção do meio ambiente. A atividade turística dentro de parques urbanos possibilita a preservação dos fragmentos florestais trazendo benefícios, como a qualificação da infraestrutura local, dos profissionais envolvidos, aumento da consciência ambiental, do sentimento de pertencimento dos residentes bem como o aumento da permanência de turistas e do fluxo de visitantes que buscam por essa conexão com o meio natural dentro da paisagem urbana. Manaus, sendo um destino turístico internacional, possui um apelo natural, o que por consequência leva à necessidade da prática do turismo sustentável possibilitando que seus inúmeros espaços verdes possam ser protegidos e trabalhados de forma séria.

Palavras-Chave: Unidades de Conservação, Turismo Sustentável, Parques Urbanos.

\section{Abstract:}

The development of tourism activity in an environment of Conservation Units is due to the need of the connection between man and the natural environment and through this connection can contribute in a qualitative way in the preservation, propagation and sustainable use of green spaces. And, for this activity to be developed in a positive and not predatory way, it must be planned and have a totally sustainable meaning. The great demand for these natural areas, mostly for Conservation Units, implies positive factors in the relationship between man and nature, education and environmental awareness, sustainable practices and protection of the environment. The tourist activity within Urban Parks makes possible the preservation of forest fragments, bringing benefits such as the qualification of the local infrastructure, the professionals involved, increased environmental awareness, the sense of belonging of the residents as well as the increase of the permanence of tourists and the flow of Visitors seeking this connection with the natural environment within the urban landscape. Manaus being an international tourist destination, has a natural appeal, which consequently leads to the need to practice sustainable tourism, enabling its many green spaces to be protected and worked in a serious manner.

KEYWORDS: Conservation Units, Planning, Sustainable Tourism.

\section{Resumen:}

El desarrollo de la actividad turística en ambiente de Unidades de Conservación se da en la necesidad de la conexión entre hombre y el medio natural y, a través de esta conexión puede contribuir de forma cualitativa en la preservación, propagación y uso sostenible de los espacios verdes. Y, para que esa actividad pueda ser desarrollada de forma positiva y no predatoria es necesario que sea planeada y tenga un sentido totalmente sustentable. La gran demanda por esas áreas naturales, en su mayoría por Unidades de Conservación, implica en factores positivos en la relación del hombre con la naturaleza, en la educación y conciencia ambiental, 
prácticas sostenibles y la protección del medio ambiente. La actividad turística dentro de Parques Urbanos posibilita la preservación de los fragmentos forestales, trayendo beneficios como la calificación de la infraestructura local, de los profesionales involucrados, aumento de la conciencia ambiental, del sentimiento de pertenencia de los residentes así como el aumento de la permanencia de turistas y del flujo de turistas Los visitantes que buscan esa conexión con el medio natural dentro del paisaje urbano. Manaus siendo un destino turístico internacional, posee un atractivo natural, lo que por consiguiente lleva a la necesidad de la práctica del turismo sostenible posibilitando que sus innumerables espacios verdes puedan ser protegidos y trabajados de forma seria.

Palabras clave: Unidades de Conservación, Turismo Sostenible, Parques Urbanos.

\section{INTRODUÇÃO}

Em se tratando da atividade turística, no decorrer dos anos, com o grande e acelerado avanço das cidades e centros urbanos, da rotina cada vez mais avassaladora, de todo o estresse do dia a dia, o ser humano está criando a necessidade de planejar mais suas viagens e experiências turísticas bem como da ânsia por estar em contato com o meio natural, de se aproximar cada vez mais da natureza, fugindo de toda a problemática da rotina. Essa grande procura por áreas naturais, em sua maioria por Unidades de Conservação (UC) no Brasil, implica em fatores positivos na relação do homem com a natureza, na educação e consciência ambiental, práticas sustentáveis e a proteção do meio ambiente.

O Brasil é um país que se destaca por sua rica biodiversidade, possui meio natural que fornece inúmeros recursos necessários para a vida, e este deve ser preservado e protegido, assim, o governo tem a responsabilidade de proteger as áreas naturais por meio da criação de Unidades de Conservação (UC). O termo Unidade de Conservação (UC) é utilizado pelo Sistema Nacional de Unidades de Conservação da Natureza (Snuc - Lei no 9.985, de 18 de julho de 2000) que corresponde às áreas naturais suscetíveis de proteção por suas características.

O debate e o levantamento de dados acerca dessa questão são de suma importância, tendo em vista que a modalidade de turismo sustentável é uma vertente que vem ganhando cada vez mais praticantes e simpatizantes ao redor do mundo, e, nesse sentido, o trade turístico e o turismólogo devem atentar-se para a necessidade de desenvolver o turismo em Unidades de Conservação não somente com a finalidade lucrativa, mas também da responsabilidade social e sustentável para com a proteção desses ambientes.

Esta é uma pesquisa qualitativa, do tipo estudo de caso, na qual as coletas de dados se deram por meio de fontes secundárias e bibliográficas. Tal estudo possibilita a discussão e reflexão quanto ao aproveitamento turístico subaproveitado desses parques bem como reforça as bases acadêmicas dos pressupostos teóricos utilizados, oportunizando novas opções de lazer e sensibilidade ambiental à sociedade manauara e oferecendo possibilidades de diversificação na atratividade turística da cidade de Manaus.

Com a referida pesquisa, evidencia-se que atividade turística dentro de parques ambientais traz em linhas gerais benefícios como: a qualificação da infraestrutura local e dos profissionais envolvidos com a questão, aumento do fluxo de visitantes que buscam por essa conexão com o meio natural, promoção do turismo em parques naturais e a ressignificação da comunidade local ao proporcionar a experiência de participar ativamente da construção e preservação de Unidades de Conservação.

\section{PLANEJAMENTO E DESENVOLVIMENTO DA ATIVIDADE TURÍSTICA NOS PARQUES URBANOS}

A atividade turística tem uma grande influência no que tange ao desenvolvimento socioeconômico. Possui ainda a responsabilidade importante da conservação do meio natural, sendo a única atividade que pode aliar geração de renda e emprego à conservação do meio ambiente natural. Quanto ao conceito de planejamento, Ignarra (2003, p. 81) afirma que pode ser considerado como a formulação sistemática de um conjunto 
de decisões, devidamente integrado, que expressa os propósitos de uma empresa e condiciona os meios de alcançá-los. E ainda segundo o mesmo autor (2003, p. 81):

O planejamento consiste na definição dos objetivos, na ordenação dos recursos materiais e humanos, na determinação dos métodos e formas de organização, no estabelecimento das medidas de tempo, quantidade e qualidade, na localização espacial das atividades e outras especificações necessárias.

É notório que mediante um bom planejamento, seja possível chegar com maior precisão ao diagnóstico de problemas que possam vir a ocorrer no futuro e ter a capacidade de evitá-los. No que se refere ao Planejamento Turístico, Ruschmann (2015, p. 8) afirma que este não deve abranger apenas um recurso (ou localidade), mas também o seu entorno.

O desenvolvimento da atividade turística pode se dar de forma acelerada, bem como pode ocorrer o estado de estagnação e declínio. Dessa forma, o planejamento deve, além de objetivar o crescimento, atentar para fazê-lo de forma controlada e sustentada, pois uma das preocupações dos planejadores na atualidade é realizar um planejamento de turismo sustentável, fazendo com que haja o desenvolvimento qualitativo.

No que compete à atividade turística no sentido do planejamento, Silva (2007, p. 69) afirma que:

A indústria do turismo tem produzido espaços delimitados especialmente destinados a variados tipos de consumo por meio dos denominados serviços do turismo, que envolvem gama extensa de empresas e pessoas que articulam os atrativos dos quais o turismo se apropria (naturais, culturais e construídos) para uso dos turistas.

Ainda em se tratando de planejamento, o referido autor afirma que ele se faz necessário como um instrumento para a utilização não predatória do patrimônio natural e sociocultural, a fim de estimular a qualidade da implantação da atividade turística (SILVA, 2007, p. 144).

Com a grande expansão das cidades e com o ritmo acelerado das cidades industriais, os parques urbanos surgem do anseio e da necessidade de suprir a demanda de práticas de lazer. Os parques urbanos são estruturas que se unem à natureza caracterizando um espaço de socialização que visa contribuir para a qualidade de vida da população.

As reservas naturais são espaços verdes que proporcionam aos residentes o contato com a natureza e a qualidade ambiental. Muitos desses espaços surgiram da necessidade da integração do homem com o meio ambiente. Com função ecológica, de estética e lazer, são estes estabelecimentos de relações sociais e de convivência em comunidade.

\section{PRÁTICAS DE ATIVIDADES TURÍSTICAS EM UNIDADES DE CONSERVAÇÃO}

Quanto ao desenvolvimento da prática do turismo em Unidades de Conservação - UCs, Santos e Carvalho (2015, p. 2) concluem que:

Há vários tipos de turismo que servem a diferentes perfis de turistas. Entre todos, o turismo de natureza é um dos que mais têm crescido. E, numa linha de coerência, esse segmento turístico nos remete à compatibilização inevitável de sua prática em Unidades de Conservação (UC), sobretudo em parques nacionais.

As Unidades de Conservação (UC) que já desenvolvem a prática do Turismo Sustentável com visitação têm sido excelentes exemplos de que, se utilizando dessa ferramenta, é possível obter um grande alcance das metas que estão voltadas para a preservação, conservação e responsabilidade ambiental, e o desenvolvimento no âmbito socioeconômico e sustentável. Desenvolver a atividade turística em parques ambientais não é uma novidade, tanto no exterior quanto no Brasil. No continente brasileiro, por meio do Ministério do Meio Ambiente, o Instituto Chico Mendes de Conservação da Biodiversidade, Ministério do Turismo e Instituto Brasileiro de Turismo - Embratur, tem-se o Programa de Turismo nos Parques (2006), que abrange 25 Parques Nacionais. O programa visa estruturar e promover o turismo dos parques inseridos no Sistema Nacional de Unidades de Conservação - Snuc. 
Entre os principais objetivos do supracitado programa, tem-se a qualificação da infraestrutura e de serviços de apoio aos turistas nos parques; dinamizar a economia local e as alternativas de trabalho ligadas à atividade turística; aumentar o fluxo de visitantes do parque; aproximar a sociedade da natureza e aumentar o público para a preservação de áreas protegidas; elaborar estratégias de promoção do turismo nos parques para os públicos internos e externos; conhecer o perfil do visitante dos parques e fortalecer a capacidade das comunidades locais para a sua participação no desenvolvimento do turismo (PROGRAMA DE TURISMO NOS PARQUES, 2006, p. 4 e 5).

De acordo com Dourojeanni (2011, p. 1):

Em muitos lugares do Brasil ou da América Latina existem atrativos turísticos já transformados em produtos que atraem um fluxo turístico razoável. Nesses lugares, existem muitos outros atrativos subutilizados ou mal utilizados, que se aproveitados poderiam aumentar muito a rentabilidade econômica do turismo na região, sem prejudicar e até mesmo complementando os produtos já desenvolvidos. Uma grande parte destes e os melhores estão nas áreas naturais protegidas, ou seja, nas Unidades de Conservação (UCs) federais ou estaduais.

Dourojeanni (2011, p. 3) afirma ainda que, devido à falta de investimentos nas Unidades de Conservação - UC e às modalidades inadequadas de gerenciamento, muitas delas ainda não são o que se pode qualificar como produto turístico.

Em Portugal, tem-se o Programa de Visitação e Comunicação na Rede Nacional de Áreas Protegidas, do Instituto da Conservação da Natureza - ICN. O Plano tem por objetivo implementar melhorias no que tange à visitação e ao desenvolvimento da atividade turística, causando a sensibilidade ambiental sem que haja um excessivo fluxo de turistas que venha a prejudicar o meio natural e a estrutura de visitação, mas que possa trabalhar em um equilíbrio da composição com a conservação e proteção da biodiversidade (INSTITUTO DE CONSERVAÇÃO DA NATUREZA, 2006, p. 51).

Quanto às principais dificuldades apresentadas para o desenvolvimento da prática da atividade turística em Unidades de Conservação, Dourojeanni afirma que:

As Unidades de Conservação são, no momento, o que se qualifica como "atrativos turísticos naturais brutos". Para seu aproveitamento devem ser transformados em produtos turísticos. Isso, como bem se sabe, implica em investimentos fora e dentro das UCs. Fora das UCs, o setor público deveria investir em acessos razoáveis, boa sinalização e disponibilização de informação atrativa sobre elas. Dentro delas é preciso implantá-las, ou seja, construir tudo que possibilite aos visitantes desfrutar o que a UC lhe oferece (2011, p. 8).

Nesse sentido, é notável o quão é importante o desenvolvimento da atividade turística em Unidades de Conservação, levando em consideração a gama de benefícios que se tem ao fazer a integração do turismo com os espaços verdes por meio do ecoturismo. De acordo com Backes e Rudzewicz (2012, p. 4):

A preocupação em aliar conservação, turismo e natureza tem contribuído para a criação e manutenção das Unidades de Conservação (UC) no Brasil, incentivando as pessoas a uma nova percepção turística, mais preocupada com a preservação da natureza e do meio ambiente.

Essa interação entre homem e a natureza é um processo em que ambas as partes têm ganhos extremamente positivos, pois é possível dinamizar por meio do turismo em áreas protegidas, melhorias na estrutura dos parques bem como avanços que seriam empregados para a população no entorno. Em contrapartida, haverá a sensibilização ambiental para a proteção das Unidades de Conservação e o bem-estar dessa conexão entre as pessoas e o meio natural. Os autores Santos e Carvalho ressaltam que:

Em paralelo, o incremento da visitação aos parques nacionais, que atualmente sofrem de uma falta crônica de recursos, pode reverter em solução para problemas como falta de funcionários, ausência de planos de manejo, fiscalização deficiente, entre outros $(2015$, p. 3).

A atividade turística permite, quando realizada e planejada de forma correta e responsável, a geração de emprego e renda, oferta de lazer e recreação, a propagação da cidadania e interação social sem distinção de 
público, atrelando sempre o turismo ao desenvolvimento sustentável, elo este que é imprescindível na relação entre as pessoas e a proteção do meio natural. O sucesso dessa dinâmica só se dá de forma satisfatória quando há uma gestão de turismo inteligente, sensível e responsável (SANTOS; CARVALHO, 2015, p. 2). Os mesmos autores relatam que:

Com isso em mente, incumbe, pois, ao Poder Público o estímulo e regulação do desenvolvimento do turismo de modo a beneficiar a comunidade local sob a forma de infraestrutura básica e de implementação de leis em prol da melhoria da saúde pública, da segurança, do meio ambiente, do oferecimento de facilidades públicas (estacionamentos, praças e jardins, por exemplo), da promoção da imagem e marketing do destino e do estímulo à hospitalidade da comunidade (criação de Centro de Visitantes, por exemplo). Ainda, a atuação governamental deve se pautar em estratégias claras para a implementação de uma política de turismo local e regional, tudo isso com vistas às metas a serem alcançadas e com base em planejamento participativo (SANTOS; CARVALHO, 2015, p. 6).

O ecoturismo implica em várias oportunidades para que a atividade turística seja desenvolvida de forma totalmente benéfica, causando o mínimo de impactos na área natural e procurando respeitar a cultura local, envolver os principais agentes de interesse, como a comunidade local, instituições governamentais do viés de proteção do meio natural, turismólogos, planejadores, instituições de ensino, entre outros. Além de gerar emprego e renda para a população, também contribui para a conservação da área protegida e promove a educação e a responsabilidade socioambiental quanto ao seu papel de sustentabilidade nas mais diversas esferas da sociedade. Trabalhar essa consciência ambiental resulta diretamente na postura do ser humano no que tange a sua inclusão na sociedade como um ser ativamente engajado e com uma visão mais sensível e branda. Assim, Costa Júnior complementa que:

Contudo, para que o ecoturismo proporcione benefícios, como citado anteriormente, é necessário um planejamento e monitoramento das atividades desenvolvidas para conseguir uma relação harmoniosa entre ecoturismo e conservação da natureza, podendo tornar-se uma fonte de renda para a UC e a comunidade do local (2014, p. 35).

A disseminação da atividade turística em Unidades de Conservação caracteriza-se como uma nova forma de usufruir dos recursos naturais, tendo total entendimento e consciência de que esses recursos são finitos e, portanto, devem ser respeitados e preservados, trabalhando sempre a interação do turista com o meio natural e com a comunidade local. Nesse sentido, as Unidades de Conservação têm a obrigação não somente de ser um local de preservação do meio natural, mas também de tornar esses espaços ideais para a realização de práticas de lazer e atividades físicas, recreação, pesquisa, interação social e a atividade turística (COSTA JÚNIOR, 2014).

É imprescindível que haja a construção de estratégias e metodologias de planejamento que possam permitir essa interação de forma coerente e sem causar danos à Unidade de Conservação e à comunidade local, adotando ações de manejo que visem a diminuição e erradicação dos impactos negativos. Os autores Fontoura e Silveira (2006), nesse sentido, afirmam que:

Para se alcançar o desenvolvimento equilibrado do ecoturismo, em consonância com os preceitos de preservação das áreas naturais, é necessário estabelecer mecanismos de planejamento e de gestão ambiental dinâmicos, flexíveis e integrados. $\mathrm{O}$ planejamento deve garantir, ao mesmo tempo, a conservação dos recursos naturais e o uso turístico em harmonia com os interesses e necessidades dos diversos atores sociais envolvidos (2006, p. 6).

Então, é importante o desenvolvimento de atividades que envolvam em conjunto a sociedade e o meio natural, no caso o cidadão e o turista em união com as Unidades de Conservação, promovendo a sustentabilidade, a consciência ambiental, a interação e o respeito entre homem e meio ambiente, corroborando ferramentas que auxiliem no planejamento e disseminação da atividade, e a promoção desses locais, dando-os visão e reconhecimento. Santos afirma que a atividade turística só é sustentável quando:

[...] passamos a ter atitudes que somem com o meio ambiente. A educação ambiental é uma ferramenta importante nesse processo, pois atua na sensibilização das pessoas promovendo posturas e atitudes adequadas ao ambiente que possam trazer benefícios recíprocos e para as futuras gerações. (2014, p. 18) 
É necessário ter em mente que o planejamento e a gestão do meio natural aumentam significativamente o interesse das pessoas em conhecer esses locais com o intuito de estar em contato com a natureza, compreender o meio natural e, por meio dessa atividade, superar o estresse urbano vivido nas grandes cidades.

\section{O CONTEXTO TURíSTICO DOS PARQUES URBANOS DE MANAUS}

Para que seja possível a compreensão desta pesquisa, é necessário conhecer alguns conceitos acerca de áreas verdes e parques urbanos, bem como a sua importância no contexto social e cultural de uma cidade e na relação destes com a integração do homem e áreas naturais. Reconhecendo, assim, as principais opções de parques urbanos na cidade de Manaus, que, em relação ao seu relevante número e tamanho geográfico, não se aproxima de um número satisfatório que venha a atender as demandas de fluxo de visitação e turismo.

As áreas verdes podem ser interpretadas como áreas de vegetação que compõem parques, jardins, cemitérios, alamedas, bosques, praças, balneários, campings, entre outros (CAVALHEIRO; DEL PICCHIA, 1992). Os termos, como área verde, verde urbano, espaços livres e parques urbanos, são comumente utilizados para retratar a conexão da cidade com os ambientes naturais. De acordo com Cavalheiro e Del Picchia:

Os espaços livres desempenham basicamente papel ecológico, no amplo sentido, de integrador de espaços diferentes, baseando-se, tanto no enfoque estético como ecológico e de oferta de áreas para o desempenho de lazer ao ar livre. (1992, p. 31).

Esses espaços verdes desempenham um papel fundamental na qualidade de vida da população das cidades, sendo utilizados como meio de preservação dos fragmentos naturais existentes meio ao crescimento das cidades e ainda para a prática e desenvolvimento de lazer e entretenimento. Pode-se conceituar parque urbano como áreas verdes e espaços livres que recebem a responsabilidade de desempenhar um papel social e ecológico e que causam impacto positivo na estrutura da cidade por meio da estética. Assim, Melo e Dias afirmam que "os parques urbanos são representativos para o lazer da cidade por serem capazes de estabelecer relações sociais por meio das atividades esportivas, culturais, educativas, artísticas, ambientais e contemplativas" (2013, p. 1). Em um modo abrangente, de acordo com Matias (2006, p. 45 e 46), podem-se aplicar ao conceito de parque urbano as seguintes funções:

1. Função Ecológica: desenvolver a preservação do meio natural presente na cidade;

2. Função Social: possibilitar a integração social e as práticas de lazer e entretenimento;

3. Função Educativa: desenvolvimento de atividades complementares visando desenvolver nos alunos a consciência ambiental;

4. Função Psicológica: proporcionar a conexão do homem com o meio natural para distrair das tensões do cotidiano, a prática de exercícios físicos e recreação.

O uso desses espaços só será de qualidade quando se pensa na manutenção, conservação e segurança. Matias (2006, p. 54) expõe que:

A conservação e manutenção de todos os elementos que compõem uma praça ou um parque, por menor que possam parecer, devem merecer atenção continuada não só do Poder Público, gerenciador dessas áreas, mas também da população que as utiliza.

Ainda em se tratando da manutenção dos parques urbanos, Simonetti e Pereira (2013, p. 5) concluem que:

A conservação de áreas construídas ou naturais está intimamente relacionada ao uso que a população faz desses espaços. Portanto, o planejamento e manejo de parques e outros espaços livres devem ser realizados englobando os desejos e expectativas de seus frequentadores.

No que tange à ligação dos parques urbanos com a atividade turística, a paisagem é um elemento de extrema sedução para os visitantes e turistas, implicando em uma grande propagação para que o local venha a se 
tornar uma atração turística. Assim, Simonetti e Pereira (2013, p. 6) corroboram que a exploração turística de parques proporciona uma vivência mais rica dentro da cidade, despertando a valorização e compreensão da importância do ambiente natural do lugar em que se vive.

Nesse sentido, a utilização dos parques urbanos para a realização de práticas de lazer e turismo carece de um projeto harmonioso que garanta um espaço de socialização e integrador entre os vários temas que permeiam a multidisciplinaridade da atividade turística como: educação, meio ambiente, cultura, geografia, entre outros. Melo, Nóbrega e Dias concluem que:

Percebe-se, então, que os parques urbanos são como antídotos para os males urbanos: melhoram o clima, contrapondose à aridez provocada pelo excesso de construções urbanas; diminuem a poluição do ar; enfim, permitem o contato com a natureza, entre outros (2012, p. 3).

O crescimento demasiado da cidade e o desenvolvimento sem um planejamento que visasse a preservação dos espaços verdes fizeram com que a cidade de Manaus tivesse uma grande perda da vegetação existente e da qualidade do clima e ar. A cidade não cresceu na mesma proporção de suas áreas verdes, ocasionando um prejuízo na qualidade de vida e no bem-estar da população manauara. Dessa forma, é extremamente importante o cuidado dos parques urbanos e áreas verdes presentes com o objetivo de proporcionar a convivência equilibrada entre a natureza e o urbano no desenvolvimento socioeconômico e ambiental da capital amazonense.

Quanto aos parques existentes na cidade, Moraes et al. (2014) evidenciam que ainda hoje a cidade de Manaus oferece uma quantidade ínfima de parques urbanos, se viermos a considerar toda a dimensão de seu espaço urbano. Manaus possui algumas opções de parques urbanos, entre eles pode-se citar o Parque dos Bilhares (Figura 1), que foi inaugurado pela prefeitura no dia 24 de outubro de 2006, com cerca de 60.000 $\mathrm{m}^{2}$, tendo como principal objetivo oferecer uma nova opção de lazer e entretenimento à população e ainda contribuir para a preservação do meio ambiente por encontrar-se no limite de dois igarapés.

Entre as atrações que compõem o parque, está a biblioteca, que possui um vasto e rico acervo de livros infantis e espaço educativo (equipada com conexão à internet) que estimula a leitura, contribuindo também para a inclusão digital. Possui quadras poliesportivas, pista de skate e playground, criado para a interação das crianças. Dispõe, ainda, de sorveteria e tacacaria, tornando o local um ambiente propício para o lazer e a descontração (SEMAS, 2016).

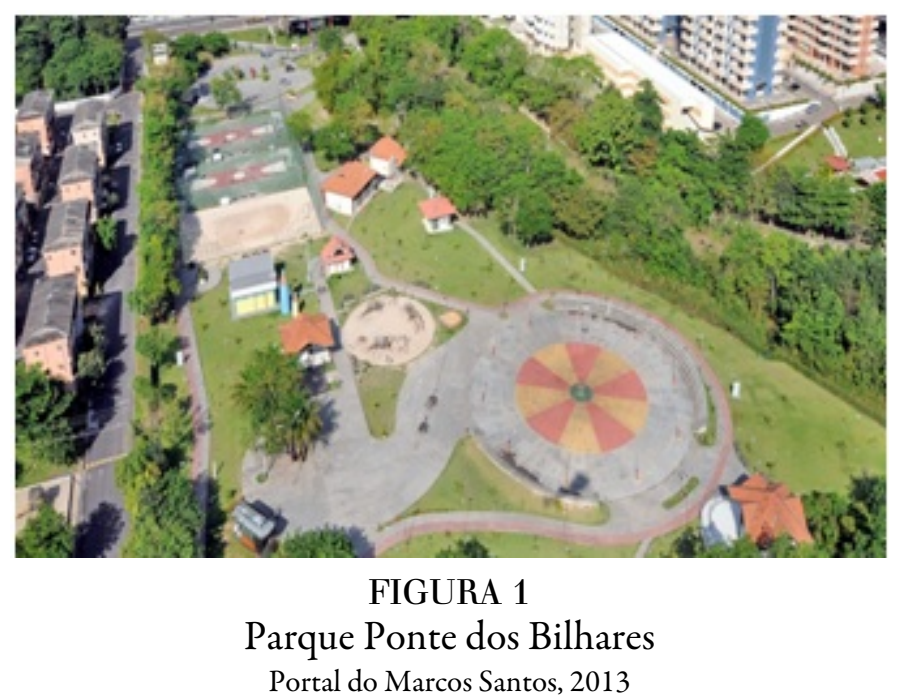

A cidade tem ainda o Parque Municipal do Mindu (Figura 2), que possui 33 hectares de vegetação e foi criado em 1989, por meio de um manifesto popular dos moradores das adjacências do parque, com o intuito 
de proteger o habitat do Sauim-de-Manaus. O local integra uma biblioteca com estoque de 2.000 livros e um complexo de trilhas. O parque promove atividades de responsabilidade ambiental e cultural (SEMAS, 2016).

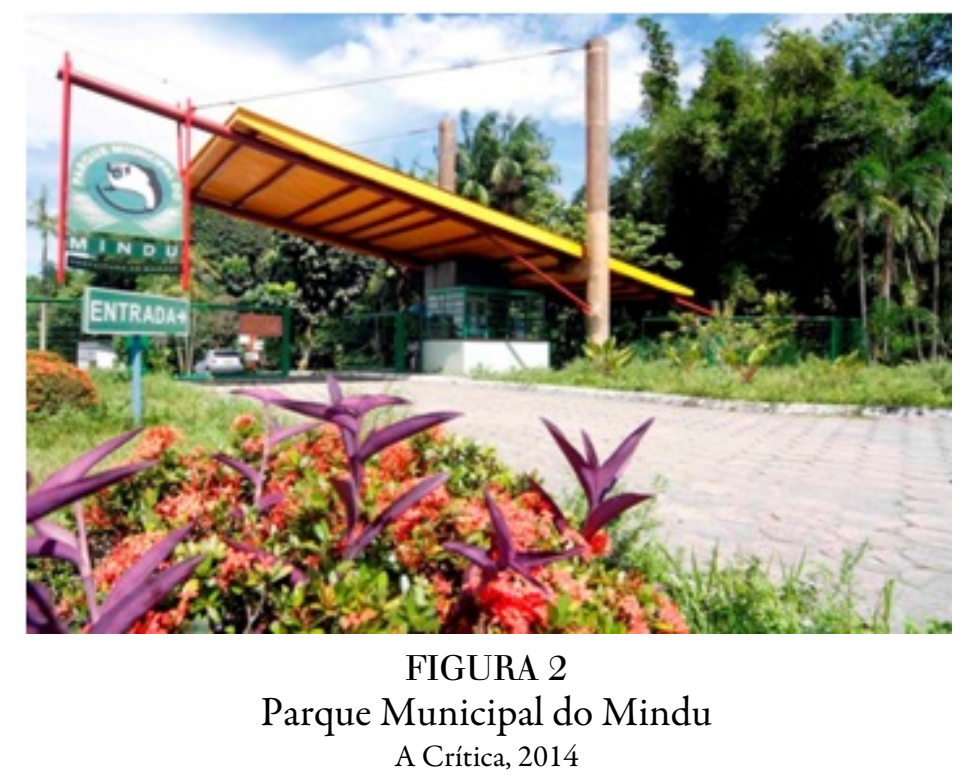

Outra opção de parque urbano é o Jardim Botânico Adolpho Ducke (Figura 3), conhecido também como Museu da Amazônia - Musa, que foi criado em 2000 pela Prefeitura de Manaus em parceria com o Instituto Nacional de Pesquisa da Amazônia, tendo como objetivo principal a contenção do avanço da ocupação desordenada e proteção da área verde. O Jardim Botânico Adolpho Ducke oferece uma biblioteca, lanchonete, trilhas ecológicas e o principal atrativo, que é a torre de observação de 42 metros, permitindo uma visão privilegiada de $360^{\circ}$ de toda a vegetação (MORAES et al., 2014).

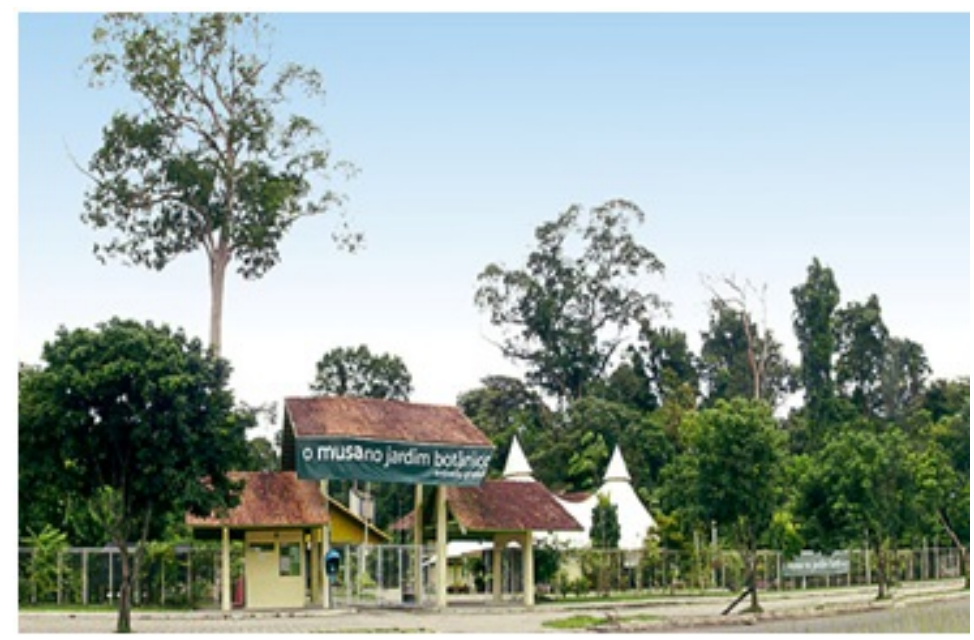

FIGURA 3

Jardim Botânico Adolpho Ducke Jardim Botânico de Manaus, 2012

Tem-se ainda o Bosque da Ciência (Figura 4), que foi inaugurado em $1^{\circ}$ de abril de 1995 com o intuito da realização do projeto de abrir ao público a visitação do Instituto Nacional de Pesquisas da Amazônia Inpa, como parte da comemoração dos 40 anos do Instituto. $\mathrm{O}$ bosque está estabelecido no perímetro urbano da cidade detendo o total de 13 hectares de área. O principal objetivo do parque é fornecer uma opção de lazer de caráter sociocientífico e cultural, aguçando nos visitantes o interesse pelo meio natural (MORAES et al., 2014). 


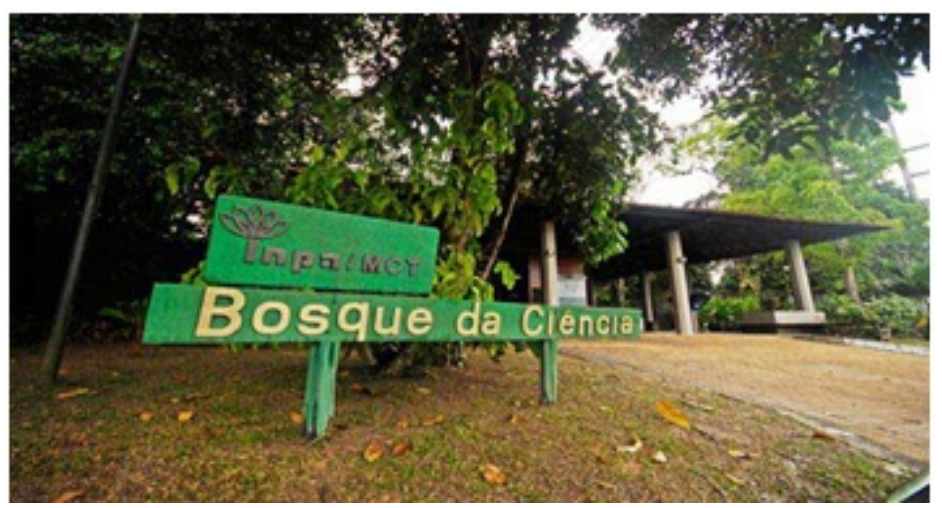

FIGURA 4

Bosque da Ciência

Em Tempo, 2016

Inaugurado em 2002, tem-se a opção do Parque Municipal do Idoso - Fundação Dr. Thomas (Figura 5) com uma área de $11 \mathrm{mil} \mathrm{m}^{2}$. O local é aberto ao público em geral e oferece aos visitantes piscina, ginásio poliesportivo coberto, auditório, pista de caminhada, lanchonete, restaurante e salão de beleza (MORAES et al., 2014).

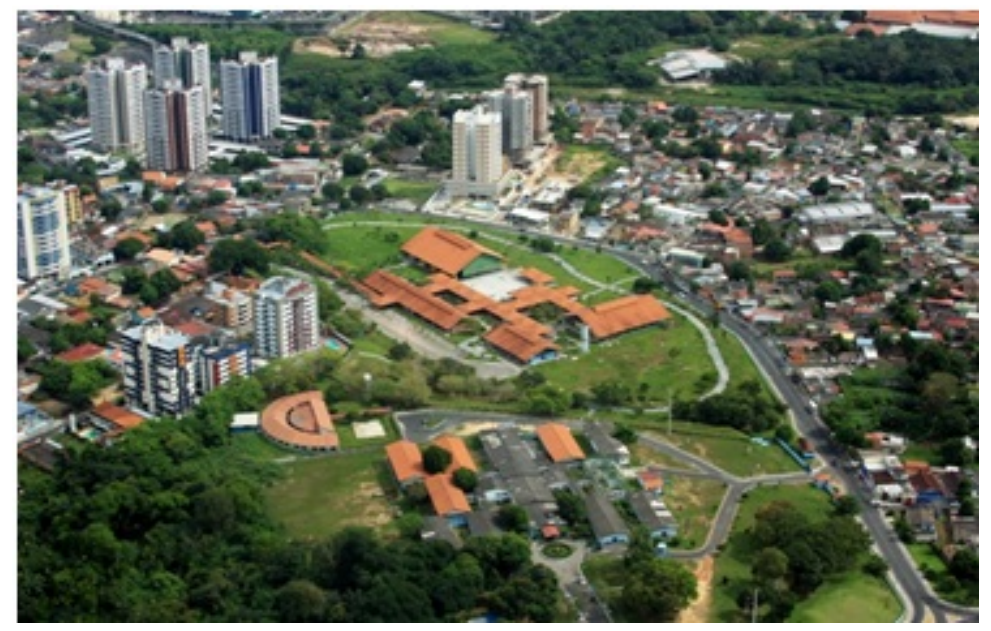

FIGURA 5

Parque Municipal do Idoso

Portal do Zacarias, 2014

O Parque Cidade da Criança (Figura 6), ativo desde 2012, foi instalado nas dependências do antigo Horto Municipal. O parque é o único temático na cidade e ocupa a uma área de dois hectares com a presença significativa de espaços verdes. Além disso, oferece opções de entretenimento, brincadeiras lúdicas, espetáculos infantis, entre outras (MORAES et al., 2014). 


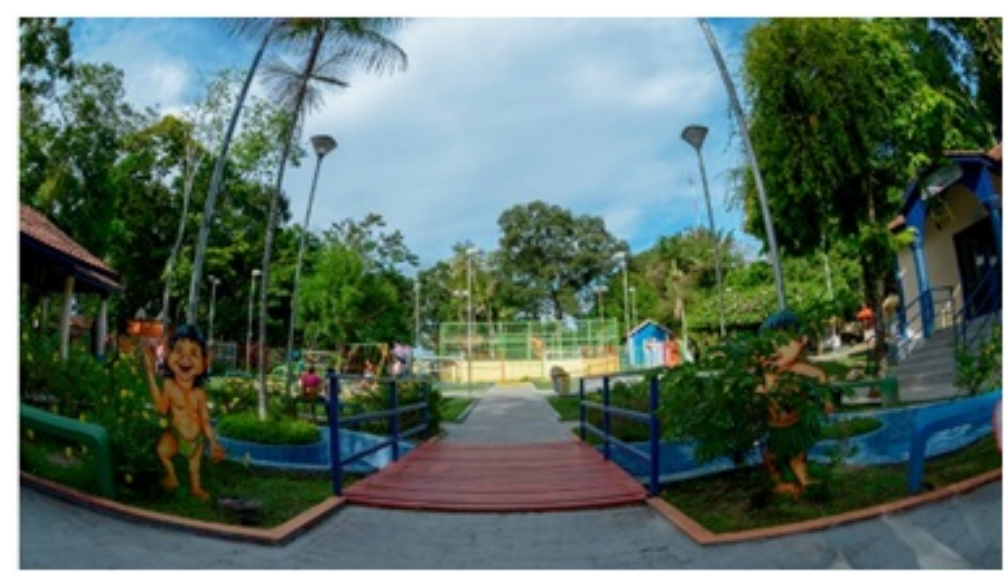

FIGURA 6

Parque Cidade da Criança

Portal Amazônia, 2016

O Parque Lagoa do Japiim (Figura 7) ocupa uma área de $40 \mathrm{mil} \mathrm{m}^{2}$ e foi inaugurado em 2008. O parque possui uma lagoa e abriga uma estação de tratamento de efluentes - ETE, que visa melhorias na qualidade da água e remediar o problema de mau cheiro oriundo de matérias orgânicas do lago. É possível avistar em certos momentos a permanência de alguns quelônios que ficam à mostra ao final da tarde. O parque possui arborização e um complexo que permite a prática de atividades físicas. Futuramente, com a despoluição total do lago, há um projeto da prefeitura que pretende iniciar a realização de passeios de canoas pela extensão do lago (SEMAS, 2016).

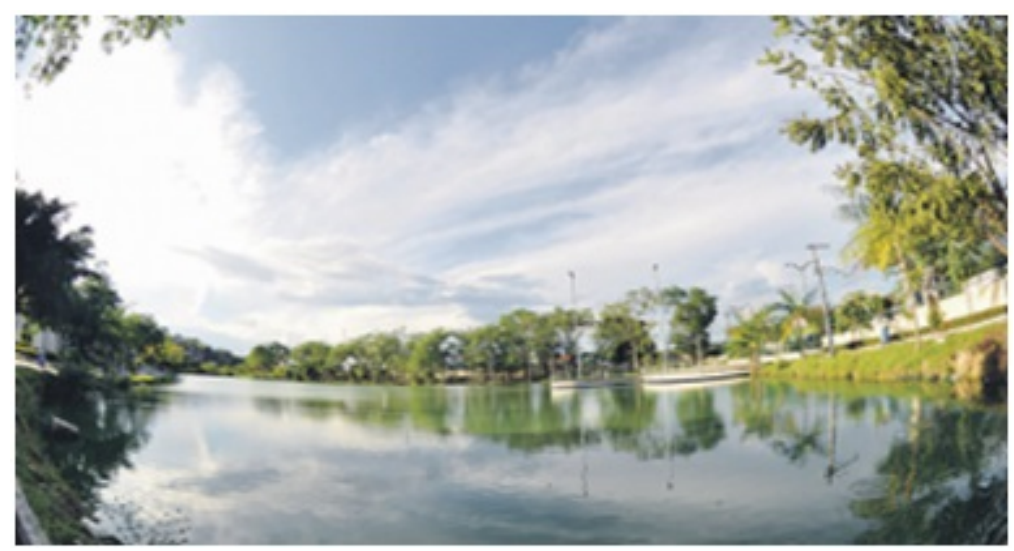

FIGURA 7

Parque Lagoa do Japiim

Rede Tiradentes, 2015

Uma das principais atrações turísticas de Manaus é o Complexo Turístico Ponta Negra (Figuras 8 e 9), um dos principais cartões-postais da cidade e que foi palco do Fifa Fan Fest ${ }^{\text {tix }}$ na Copa do Mundo de 2014. O local abriga nos tempos atuais o tradicional desfile de 7 de setembro, realizado pelo Governo do Estado e Forças Armadas. $\mathrm{O}$ espaço conta com calçadão com pedras portuguesas, jardins, praça com chafariz, mirantes com vista para o Rio Negro, mais vagas para estacionamento, quadras poliesportivas e um novo anfiteatro. O seu entorno conta ainda com uma diversidade de quiosques e restaurantes com vários tipos de culinária, desde a tradicional e local até pratos gourmet e requintados. É administrado pela Prefeitura de Manaus por meio do Instituto Municipal de Ordem Social e Planejamento Urbano - Implurb. (PREFEITURA DE MANAUS, 2014). 


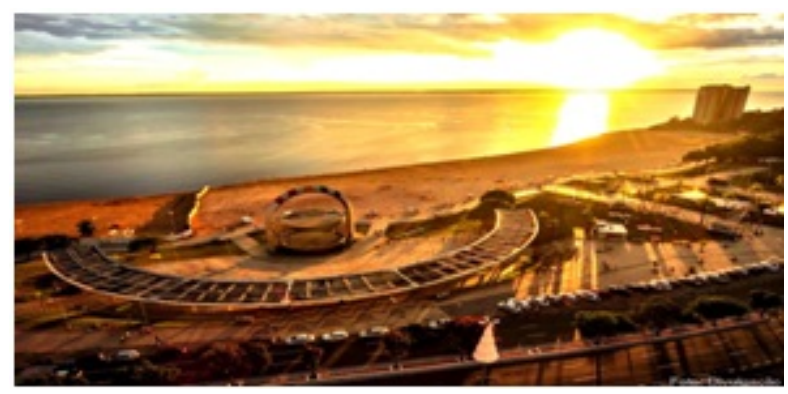

FIGURA 8

Complexo Turístico Ponta Negra

Portal do Amazonas, 2014

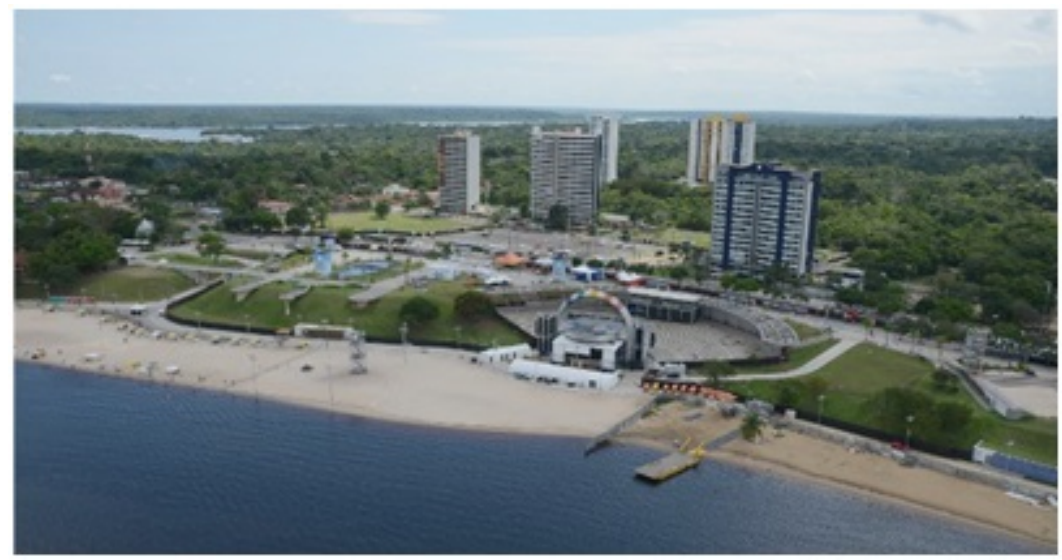

FIGURA 9

Complexo Turístico Ponta Negra

Portal da Amazônia, 2014

Para a prática de esportes, tem-se um lugar seguro e acessível para se exercitar, pode-se aproveitar o calçadão para fazer caminhadas e corridas. $\mathrm{O}$ complexo também reúne grande público que aproveita o espaço destinado ao "Faixa Liberada", da Secretaria Municipal de Juventude, Esporte e Lazer (Semjel). O projeto consiste na interdição da Avenida Coronel Teixeira, no sentido bairro-centro, para práticas esportivas, das $17 \mathrm{~h}$ às $22 \mathrm{~h}$ às quartas, e aos domingos das $6 \mathrm{~h}$ às $12 \mathrm{~h}$. Às quartas-feiras o projeto disponibiliza $1,3 \mathrm{~km}$ de pista, e aos domingos, por conta da maior demanda, o público conta com $2,5 \mathrm{~km}$ de pista liberada. Os ciclistas contam também com uma Estação de Reparos Rápidos de Bicicletas, equipada com um conjunto de ferramentas básicas para reparos nas bikes, como chaves e bomba de ar (PREFEITURA DE MANAUS, 2014).

$\mathrm{Na}$ zona norte da cidade tem-se ainda o Parque Estadual Sumaúma (Figura 10), que é um fragmento de floresta localizado na malha urbana do bairro Cidade Nova. Segundo a Secretaria de Estado do Meio Ambiente - Sema, o parque possui título de primeira Unidade de Conservação do estado. O local possui itens de cenografia artística no interior do seu ambiente. Essa construção cenográfica deu ao parque oito ambientes temáticos, incluindo o portal. O parque dispõe ainda de um espaço aberto com dez equipamentos funcionais que são disponibilizados livremente e sem custo algum para os visitantes realizarem atividades físicas em meio ao ambiente natural. Há ainda um espaço dedicado às crianças, denominado Parque Encantado da Criança, que possui alguns brinquedos e monumentos do lendário amazônico, como o Curupira e de animais como a onça-pintada. O local, que possui lixeiras seletivas, dispõe também de um observatório de 17 metros, que recebeu o nome de Árvore da Vida), e uma rampa auxiliar, chamada de Folha. A subida em ambos só é permitida com acompanhamento de guias, e possui capacidade para oito pessoas por subida, na qual se tem uma vista panorâmica geral do parque e seus arredores, sendo possível visualizar as espécies de Sumaúma, que dão nome ao parque. 


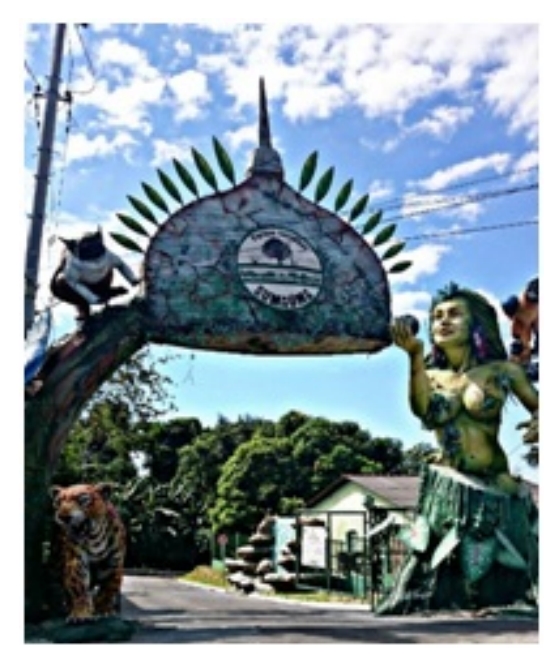

FIGURA 10

Parque Estadual Sumaúma

Autor da Pesquisa, 2016

É perceptível que existe até então um número pequeno e ineficiente de parques urbanos, quando se considera a cidade de Manaus uma metrópole populosa. É necessário que se trabalhe um planejamento mais eficaz para a cidade na relação da população com os espaços livres e a preservação e propagação dos espaços naturais em meio ao concreto urbano. Manaus é uma cidade-metrópole que tem o privilégio de estar estabelecida em meio à floresta amazônica, e é preciso recordar sempre que a conexão do homem com a natureza é de suma importância para o bem-estar físico e social. Chega a ser ultrajante uma capital com a regalia de ter em sua malha urbana ainda muitos resquícios de espaços verdes, não trabalhar para preservar e perpetuar esses locais. Esse tipo de ação visa a qualidade de vida dos citadinos e da cidade, oportunizando a eles opções de lazer mais naturais e simples, impactando significativamente a visibilidade, o que, por consequência, poderia atrair cada vez mais turistas para a capital manauara.

É necessário evidenciar a necessidade de se trabalhar a potencialidade dos parques urbanos na cidade, de pensar em estratégias que venham a captar mais visitantes para essas áreas, contribuindo para o aumento qualitativo de propagação do conhecimento acerca desses locais. Trabalhar também em melhorias na estrutura física e funcional desses parques, fazendo com que a atividade turística possa ser realizada de forma correta, eficiente e sustentável.

\section{CONSIDERAÇÕES FINAIS}

A atividade turística em Unidades de Conservação não é nenhuma novidade no âmbito do turismo, como foi possível perceber pelos exemplos apresentados no referido trabalho. Com a variedade de parques urbanos existente na cidade de Manaus, é de grande importância conhecer, debater e evidenciar condições favoráveis ao desenvolvimento da atividade.

Foi realizado, então, este estudo com base no referencial teórico e abordaram-se conceitos que demonstraram a importância do turismo na disseminação, enriquecimento da informação bem como sua contribuição para a formação dos sentidos sociais, culturais e a consciência ambiental dentro da perspectiva de estabelecer a relação do homem com o meio natural e o seu desenvolvimento sustentável.

Elucidou-se, com esta pesquisa, que a atividade turística tem uma função indispensável no que tange à preservação e conservação do meio natural e permite a compreensão do patrimônio natural. Quanto ao planejamento e à viabilização do desenvolvimento do turismo nos parques urbanos, tem-se uma percepção 
fundamental de que um planejamento eficiente corrobora a qualidade com que o serviço é oferecido, e é possível assim obter uma probabilidade de diagnosticar os pontos fortes e problemáticos da atividade.

Com a referida pesquisa, foi possível evidenciar os benefícios que a atividade turística desenvolvida de forma sustentável e eficaz é capaz de proporcionar para os atrativos turísticos de meio natural e como esse tipo de atividade pode contribuir significativamente para a percepção ambiental e conscientização do uso desses espaços atentando para a preservação e perpetuação da educação ambiental. É preciso que cada vez mais as diversas atividades que se apropriem dos meios naturais tragam consigo, além do desenvolvimento econômico e social, o respeito por esses espaços. Há a necessidade de buscar estabelecer o turismo em Unidades de Conservação de forma sustentável e responsável, a fim de integrar homem e natureza de forma a beneficiar ambos.

Faz-se necessário salientar que a pesquisa não se esgota por aqui, é preciso que se tenham mais estudos que destaquem a importância do desenvolvimento da atividade turística em espaços naturais contribuindo para a sua preservação e proteção. Que criem condições para que essa conexão do homem com a natureza se dê de forma qualitativa e que seja estabelecido assim como um novo nicho do mercado turístico, fazendo com que as Unidades de Conservação possam colher, por meio do turismo sustentável, benefícios para a comunidade do seu entorno e até mesmo a autopreservação.

\section{REFERENNCIAS}

AMAZONAS. Secretaria de Meio Ambiente e Sustentabilidade. O Retorno do Parque Municipal Lagoa do Japiim em Manaus. Disponível em: http://semmas.manaus.am.gov.br/o-retorno-do-parque-municipal-lagoado-japiim-em-manaus/> . Acesso em: 02 abr. 2016.

BACKES, L.; RUDZEWICZ, L. A Visão dos Turistas sobre a Experiência de Ecoturismo no Parque Estadual de Itapuã - RS. Anais do VII Seminário de Pesquisa em Turismo do Mercosul. Turismo e Paisagem: relação complexa. Caxias do Sul, UCS. 16 e 17 de novembro de 2012.

BRASIL. Ministério do Meio Ambiente; Instituto Chico Mendes de Conservação da Biodiversidade; Ministério do Turismo. Programa de Turismo nos Parques. Disponível em: http://www.mma.gov.br/estruturas/ sbf2008_dap/_publicacao/149_publicacao16122010111448.pdf. Acesso em: 19 abr. 2016.

CAVALHEIRO, F.; DEL PICCHIA, P. C. D. Áreas verdes: conceitos, objetivos e diretrizes para o planejamento. Encontro Nacional sobre Arborização Urbana, v. 4, p. 29-38, 1992.

COSTA JÚNIOR, J. E. V. Potencialidades ecoturísticas dos parques estaduais de Minas Gerais. Lavras: UFLA, 2014.

DOUROJEANNI, M. Parques e desenvolvimento turístico. Disponível em: http://www.oeco.org.br/colunas/marcdourojeanni/24837-areas-protegidas-e-desenvolvimento-turistico/> . Acesso em: 02 fev. 2016.

FONTOURA, L. M.; SILVEIRA, R. F. Análise da capacidade de carga antrópica nas trilhas do Circuito das Águas do Parque Estadual do Ibitipoca - MG. Monografia de especialização. Universidade Federal de Juiz de Fora. 2006.

IGNARRA, L. R. Fundamentos do Turismo. 2. ed. rev. e ampl. - São Paulo: Pioneira Thomson Learning, 2003.

INSTITUTO DA CONSERVAÇÃO DA NATUREZA. Plano de Marketing do Programa de Visitação e Comunicação na Rede Nacional de Áreas Protegidas de Portugal. Thinktur - Estudo e Gestão de Empreendimentos Turísticos. Portugal, 2006.

MATIAS, J. O. Áreas verdes urbanas como elemento da cidade sustentável. Manaus. Universidade do Estado do Amazonas - UEA, 2006.

MELO, M. I. O.; DIAS, K. S. Parques urbanos, a natureza na cidade: práticas de lazer e de turismo aliadas à cidadania. Revista Brasileira de Ecoturismo, São Paulo, v. 6, n. 5, nov-2013/2014.

MELO, M. I. O.; NÓBREGA, L. S. S. da; DIAS, K. Paisagem urbana: parque, lazer e turismo. VII SEMINÁRIO DE PESQUISA EM TURISMO DO MERCOSUL. Anais... 2012. 
MORAES, E. O. et al. As funções dos parques urbanos da cidade de Manaus. Anais Programa Ciência na Escola,v. 2, n. 1, 2014.

PEREIRA, L. F.; SIMONETTI, S. R. A percepção ambiental de frequentadores do Parque Ponte dos Bilhares em Manaus - AM. VII SEMINÁRIO DE PESQUISA EM TURISMO DO MERCOSUL. Anais... 2013.

PREFEITURA DE MANAUS. Complexo Turístico Ponta Negra é o Primeiro Atrativo da Série Conheça Manaus. Disponível em: http://www.manaus.am.gov.br/2014/09/04/complexo-turistico-ponta-negra-e-oprimeiro-atrativo-da-serie-conheca-manaus/. Acesso em: 02 abr. 2016.

RUSCHMANN, D. Turismo e planejamento sustentável: a proteção do meio ambiente [livro eletrônico]. Campinas, SP: Papirus, 2015. (Coleção Turismo).

SANTOS, J. S. dos. Turismo no parque estadual marinho de areia vermelha: praticando a (in)sustentabilidade. Instituto Federal de Educação, Ciência e Tecnologia da Paraíba - Campus Cabedelo. 2014.

SANTOS, J. da S. C.; CARVALHO, M. C. M. H. de. Turismo em parques nacionais brasileiros: conhecer para conservar. Anais Uso Público em Unidades de Conservação, v. 3, n. 3, 2015.

SILVA, C. H. C. da. Sustentabilidade e planejamento do turismo: uma discussão sobre o consumo do espaço. In: CASTELLANO, E. G.; FIGUEIREDO, R. A. de; CARVALHO, C. L. de. (Org.). (Eco)turismo, Educação Ambiental: diálogo e prática interdisciplinar. São Carlos: Rima Editora, 2007, v. 1, p. 67-84.

CC BY 